\title{
Phytochemical Profiling of Essential Oils Isolated Using Hydrodistillation and Microwave Methods and Characterization of Some Nutrients in Origanum compactum Benth from Central-Northern Morocco
}

\author{
Ahmed Zeroual ${ }^{1}$ (D) , El Hassan Sakar ${ }^{2,3, *(\mathbb{D})}$, Noureddine Eloutassi ${ }^{1}$, Fatima Mahjoubi ${ }^{1}$, \\ Mahdi Chaouch ${ }^{1}$, Abdellah Chaqroune ${ }^{1}$ \\ 1 Laboratory of Materials Engineering and Environment, Department of Chemistry, Faculty of Sciences Dhar Mahraz Fez, \\ Sidi Mohamed Ben Abdellah University, B.P. 1796 Fez-Atlas, 30003 Fez, Morocco; zeroualahmedbio@ gmail.com (A.Z); \\ eloutassi.noureddine@usmba.ac.ma (N.E); mahjoubi.fatima@usmba.ac.ma (F.M); chaouch.mahdi@usmba.ac.ma (MC); \\ chaqroune.abdellah@usmba.ac.ma (A.C.); \\ 2 Department of Biology, Faculty of Sciences of Tetuan, Abdelmalek Essaâdi University, B.P. 2121 Mhannech II. 93002, \\ Tetuan, Morocco; hassan.sce@gmail.com (E.H.S.); \\ 3 Laboratory of Natural Resources and Environment, Polydisciplinary Faculty of Taza, Sidi Mohamed Ben Abdellah \\ University, B.P 1223, Taza-Gare, Taza, Morocco \\ * Correspondence: hassan.sce@gmail.com;
}

Scopus Author ID 57194743663

Received: 12.08.2020; Revised: 7.09.2020; Accepted: 8.09.2020; Published: 11.09.2020

Abstract: In this work, we aimed at determining some nutrients from Origanum compactum (OC) and comparing its essential oils (OCEOs) isolated using microwave-assisted extraction (MW) and Clevenger hydrodistillation (HD). To this end, dried flowering tops from OC were subjected to nutrients screening, OCEOs were isolated separately using MW and HD and then analyzed using GC-MS. Our results showed that OC contained important amounts of moisture (58.66\%), minerals (10.26\%), mainly $\mathrm{K}$ (6.22), Ca (2.62), Mg (2.09mg/gDM), Fe (0.998), Mn (0.085 mg/gDM), proteins (5.65\%DM), chlorophyll a (1.09) and b (0.20 mg/gDM), and several amino acids. Among them, two (Ile and Leu) were essential. MW showed its superiority in terms of OCEO yield (7.41\%), total compounds $(95.57 \%)$, and almost individual compounds. These results were confirmed by the principal component analysis, which discriminated clearly MW and HD through the first component. In both techniques, thymol and carvacrol were the major constituents accounting for $78.81 \pm 0.22$ and $14.84 \pm 0.39 \%$, respectively, in the case of MW against $75.07 \pm 0.99$ and $13.03 \pm 0.30 \%$ for HD. Following our outcomes, OCEO was a thymol chemotype, and OC contained important amounts of nutrients. MW could serve as a green, efficient method over HD for OCEO isolation.

Keywords: Origanum compactum; nutrients; essential oils; thymol chemotype; microwave-assisted extraction ; green extraction.

(C) 2020 by the authors. This article is an open-access article distributed under the terms and conditions of the Creative Commons Attribution (CC BY) license (https://creativecommons.org/licenses/by/4.0/).

\section{Introduction}

Morocco is one of the main important floristic areas in northern Africa, owing to its geographical position, diverse geology, topography, climate, and ecoregion [1]. The Moroccan flora accounts for 978 endemic taxa, which represent more than half of the North African endemic species [2]. This endemic richness seems to be a result of the presence of mixed and 
well-differentiated environments, as outlined in Ranko et al. (2013) [1]. Origanum is one of the main genera within the Lamiaceae family with important endemic species.

Besides, the antibiotics' effectiveness prevalence has been reported to decrease, and multidrug resistance of microbes became a major concern to global public health, which leads to a 'post-antibiotic' era [3]. In such a context, there is a pressing need to look for novel strategies to fight against drug-resistant microorganisms. To meet this need, natural products have received much attention to seeking for new powerful antimicrobial agents as an important research question [4-6]. Indeed, recently, plants and their secondary metabolites have attracted the attention of the scientific community with an emphasis on their therapeutic potentials $[7,8]$. A huge number of plants used in folk medicine for curing different diseases have been proven to be more efficient, less expensive when compared to conventional drugs, and showing lesser or no side effects [9]. Also, various plant extracts, essential oils (EOs), and related compounds have been reported to have important antimicrobial powers $[10,11]$.

Origanum compactum Benth (O. compactum), locally known as "Zaatar" is one of the Moroccan endemic plant species belonging to the Lamiaceae family. It is a spontaneous annual plant (10-60 cm tall with bisexual, white/purple flowers grouped at the top of the flowers of the stem). O. compactum is essentially concentrated in Morocco and Andalusia (Spain). It is quite demanding in terms of moisture and grows mainly on slopes $[12,13]$. O. compactum (stem, flowers, and leaves) is widely used in folk medicine but also has many biotechnological applications, which arise from its phytochemical richness [13,14]. EO of O. compactum (OCEO) can be isolated mainly from the flowering tops. OCEO has highly appreciated with many applications thanks to its numerous biological activities, which are associated with carvacrol, thymol, p-cymene, and $\gamma$-terpinene as the main constituents as compiled in Bouyahya et al. (2020) [13]. OCEO is mainly isolated through hydrodistillation; yields in published literature were found to be the range $0.31-5.7 \%$ [15-19].

EO isolation technology has evolved to meet some considerations such as obtaining a higher yield, achieve extraction in a shorter time, but also to provide valuable EOs. In this context, the microwave method has emerged as a green, cleaner method, and a more efficient method [20]. This method was used to isolate EOs from some herbal species. Indeed, significant increases in terms of EOs yield and phytochemicals (especially oxygenated phytocompounds) as compared to conventional methods such as Clevenger hydrodistillation were evaluated for several species [21-24].

To the best of our knowledge, no detailed information regarding chemical profiling of EO isolated from $O$. compactum growing in central-northern Morocco using microwaveassisted extraction. Also, nutrients composition from this species has not been investigated before, hence the originality of this research work, which had as objectives, (i) to compare phytochemicals profiling of EOs from $O$. compactum using both microwave and Clevenger hydrodistillation extractions and (ii) to investigate some nutrients present in this species given its use as a food ingredient.

\section{Materials and Methods}

\subsection{Plant material and sample preparation.}

The plant species has been firstly authenticated by a botanist, Prof. A. Ennabili, from Higher School of Technologies (SMBA University, Fez, Morocco). At the full blooming stage, the aerial parts (flowering tops) of O. compactum were collected in May 2019 from the Bouadel 
region (at $25 \mathrm{~km}$ from Taounate Province). This region belongs to Central-northern Morocco and is characterized by a Mediterranean climate (humid in winter and semi-arid in summer). Collected plant samples were dried in a dark room in order to avoid the photo-oxidation, then crushed to a fine powder using an electric grinder [25]. The obtained powder was, therefore, subjected to phytochemical screening and essential oil (EO) isolation.

\subsection{Screening of O. compactum nutrients.}

Along with its pharmacological uses, $O$. compactum is considered an important plant food that can be used as a condiment or food ingredient [13]. In such a context, screening nutrients content could be of great interest. O. compactum powder was subjected to a chemical screening in terms of pigments, minerals, proteins, and amino acids.

\subsubsection{Pigments.}

Photosynthetic pigment contents: The leaf samples were extracted with $80 \%$ acetone, and the absorbance of supernatants was measured spectrophotometrically. Chlorophyll (chl) was determined at $\lambda=663 \mathrm{~nm}$ wavelength, while chl b was measured at $645 \mathrm{~nm}$ following the method given by Linchtenthaler (1987) [26].

\subsubsection{Moisture, ash, and proteins.}

Moisture, ash, and protein content were determined following the AOAC (Association of Official Analytical Chemists) procedures [27].

The method used to determine the moisture content (MC) in the flour consisted of measuring the weight loss after drying in a ventilated oven at $105{ }^{\circ} \mathrm{C}$ for $72 \mathrm{~h}$ at least until a constant weight was reached. MC expressed as \% was computed according to the following equation:

$$
\mathrm{MC}(\%)=\frac{\mathrm{W} 1-\mathrm{W} 2}{\mathrm{~W} 1} \times 100
$$

Where W1: weight in grams (g) of test sample before drying; W2: weight in grams (g) of the test sample after drying.

To determine protein content, we first measured the total nitrogen content by the Kjeldahl method. After titration of total nitrogen, proteins contained in the plant powder were calculated using the following equation:

$$
\text { Proteins content }(\%)=\mathrm{N} \times 6.25
$$

Where $\mathrm{N}$ is the total nitrogen obtained by the Kjeldahl method, and 6.25 is the protein-nitrogen conversation factor.

To determine ash content, about $5 \mathrm{~g}$ of plant powder were ashed at $550{ }^{\circ} \mathrm{C}$ to constant weight. After cooling down, the obtained ash was weighted, and ash content (\%) was calculated. computed using the following equation:

$$
\text { Ash content }(\%)=\frac{\text { Weight of ash }}{\text { Weight of sample }} \times 100
$$


2.2.3. Minerals determination.

A total of nine elements ( $\mathrm{Ca}, \mathrm{K}, \mathrm{Na}, \mathrm{Mg}, \mathrm{Fe}, \mathrm{Mn}, \mathrm{Zn}, \mathrm{Pb}$, and $\mathrm{Cu}$ ), were determined according to Agusa et al. (2005) [28], with slight modifications by ICP-AES (Brand Horiba Jobin Yvon, type Activa). Homogenized samples of $0.1 \mathrm{~g}$ were digested through microwave with $1.5 \mathrm{ml}$ of concentrated $\mathrm{HNO}_{3}$. The instrument was calibrated using $0.1,1.00,10.00$, and $25.00 \mathrm{mg} / \mathrm{L}$ concentrations from an ICP multi-elements Standard solution (Merck, 24 elements).

\subsubsection{Amino acids screening.}

The thin-layer chromatography (TLC) technique was applied to crude aqueous extracts for the detection of amino acid using the standard method of Harborne (1973) [29]. $25 \mathrm{~g}$ of dry powder previously prepared was mixed with $500 \mathrm{ml}$ of distilled water. This mixture was kept for $24 \mathrm{hrs}$ at room temperature, then vortexed for 3-4 min and allowed to settle down. The extract was centrifuged at $7000 \mathrm{rpm}$ for 15 minutes. The supernatant was collected and used for amino acid screening. A sample of aqueous extract was spotted on the TLC plate (plate of silica gel G). Later, spots developed by amino acids were detected by using standard reagent ninhydrin and identified by their color and reference amino acids.

\subsection{EOs isolation.}

O. compactum EOs (OCEOs) were isolated via two different methods, namely: Microwave-assisted extraction (MW) and Clevenger hydrodistillation (HD), as described below. OCEOs yields were calculated and expressed in percent per weight of the dried plant material (\% DW). The obtained EOs using both methods (MW and HD) were subjected to phytochemical profiling using gas GC-MS.

\subsubsection{OCEO isolation using MW.}

Solvent-free microwave extraction was carried out according to Lucchesi et al. (2004) [20] in a Milestone "DryDist" microwave laboratory oven, which is a multimode microwave reactor of $2.45 \mathrm{GHz}$ with a maximum power of $103 \mathrm{~W}$. During extraction, the temperature was controlled via an external infrared sensor. A plant material sample of $100 \mathrm{~g}$ was heated at atmospheric pressure using a fixed power density of $1 \mathrm{~W}$ g- 1 for 15 min without adding water or solvents. The direct interaction between microwaves and biological water (present in plant material) fosters the release of EOs contained in the plant tissues. The mixture of hot "crude juice" and in the situ water move, due to earth gravity downwards, on a spiral condenser where it can be easily condensed. In a receiving flask, oily condensate was gathered permanently. In the end, the obtained EO was collected, dried using anhydrous sodium sulfate.

\subsubsection{OCEO isolation using HD.}

To isolate $\mathrm{EO}$ from $O$. compactum, dried aerial parts were submitted to hydrodistillation by means of a Clevenger-type apparatus. Three independent distillations, each involving 100 $\mathrm{g}$ of plant material, were carried out by boiling, for a period of three hours, in a 1-liter flask topped by a column of $60 \mathrm{~cm}$ length connected with a refrigerant as described by Jennan et al. (2018) [30]. EO obtained was separated from water using decantation. EO was then dried over anhydrous sodium sulfate and kept in the dark vials at $4^{\circ} \mathrm{C}$ until use. 


\subsection{Phytochemical profiling of OCEOs using gas GC-MS.}

The analysis of EOs, obtained by both techniques (MW and HD), was performed according to the protocol described in Talbaoui et al. (2016) [31]. It was carried out on a TRACE GC ULTRA equipped with a non-polar VB5 (95\% methyl polysiloxane, and 5\% phenyl), a capillary column (30 $\mathrm{m} \times 0.25 \mathrm{~mm}$ i.d. and $0.25 \mu \mathrm{m}$ as a film thickness), connected directly to an ion-trap mass spectrometer (Polaris Q) (EI $70 \mathrm{eV}$ ). The temperatures of the injector and detector were set at 250 and $300^{\circ} \mathrm{C}$, respectively. The oven temperature was programmed to increase by $4^{\circ} \mathrm{C} / \mathrm{min}$ from 40 to $180^{\circ} \mathrm{C}$ and by $20^{\circ} \mathrm{C} / \mathrm{min}$ for $180-300^{\circ} \mathrm{C}$. Helium was used as a gas carrier with a flow rate of $1 \mathrm{~mL} / \mathrm{min}$. The samples $(1 \mu \mathrm{L}$ each) were injected following a splitless mode.

\subsection{Statistical analyses.}

All determinations and experiments were performed, at least, in triplicates. The combined analyses of variance (ANOVA) were computed to elucidate the variances of yield and chemical composition in OCEOs. Quantitative differences, among mean values, were evaluated by the general linear procedure followed by Duncan's test. Statistical analyses were performed using the SPSS package version 23 (IBM, Armonk, NY, USA). Results were expressed as means \pm standard deviations (SD). Differences were considered significant at $5 \%$ as a probability level. Principal component analysis (PCA) was carried out to discriminate extraction techniques by means of STATGRAPHICS package version XVIII (Statpoint Technologies, Inc., Virginia, USA).

\section{Results and Discussion}

\subsection{Nutrients.}

As summarized in Table 1, important amounts of mineral, proteins, and chlorophylls were found in $O$. compactum. The total mineral content was estimated to be $10.26 \%$. Mineral elements are presented in Fig. 1. Among them, the most abundant macronutrients were $\mathrm{K}$ (6.22), $\mathrm{Ca}$ (2.62), and $\mathrm{Mg}$ (2.09 $\mathrm{mg} / \mathrm{gDM})$, while the most important micronutrients were $\mathrm{Fe}$ (0.998) followed by $\mathrm{Mn}(0.085 \mathrm{mg} / \mathrm{gDM})$. The remaining micronutrients ( $\mathrm{Zn}, \mathrm{Pb}$, and $\mathrm{Cu})$ were lesser since their concentrations were below $0.01 \mathrm{mg} / \mathrm{gDM}$. Chlorophylls a and $\mathrm{b}$ were found to be 1.093 and $0.198(\mathrm{mg} / \mathrm{gDM})$, respectively. Moreover, the total protein content was $13.67 \%$ DM. As shown in Table 2, results regarding amino acid screening demonstrated the presence of eight amino acids, including Ile and Leu, as essential amino acids.

Table 1. Mean values of mineral elements, chlorophylls, and proteins in $O$. compactum aerial plants (\% DM). $\mathrm{DM}=$ dry matter.

\begin{tabular}{l|c|c|c|c|c} 
Nutrient & Moisture content (\%) & Ash (\%DM) & Proteins (\%DM) & Chl a (mg/gDM) & Chl b (mg/gDM) \\
\hline Concentration & $58.66 \pm 0.22$ & $10.26 \pm 0.12$ & $5.65 \pm 0.31$ & $1.09 \pm 0.11$ & $0.20 \pm 0.08$
\end{tabular}

Table 2. Amino acids screening in $O$. compactum Benth aerial plants (\% DM). DM = dried matter. Asp = Aspartic acid, Glu = Glutamic acid, Ala = Alanine, Arg = Arginine, cys $=$ cystine, His $=$ Histidine, Met $=$ Methionine, Phe $=$ Phenylalanine, Ile $=$ Isoleucine, Leu $=$ Leucine, Ser $=$ Serine, and Pro $=$ Proline.$+:$ present and - : absent.

\begin{tabular}{l|l|l|l|l|l|l|l|l|l|l|l|l} 
Amino acid & Asp & Glu & Ala & Arg & Cys & His & Met & Phe & Ile & Leu & Ser & Pro \\
\hline Screening & + & + & + & + & - & - & - & - & + & + & + & +
\end{tabular}


A

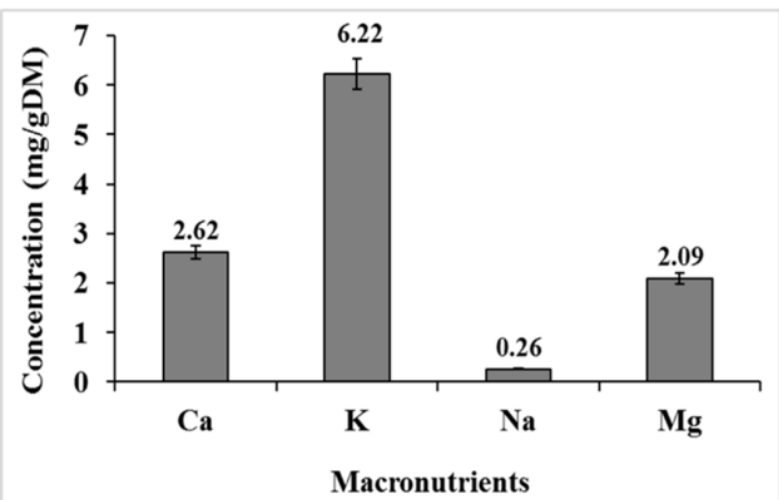

B



Figure 1. Mean values of mineral elements. A: macronutrients and B: micronutrients. Values are given as mean $\pm \mathrm{SD}$ of triplicate determinations.

In the literature, plants food, including species belonging to Origanum genus, were extensively studied for their nutrients content [32-35]. Values of moisture, ash, proteins found in our results were within the range reported by Pereira et al. (2015) [32], who investigated the chemical composition in 39 plant foods, including two species belonging to Origanum. Moreover, several primary and secondary metabolites were recently investigated in $O$. vulgare by Saleh et al. (2020) [36]. These authors confirm the presence of various minerals (mainly K, $\mathrm{P}, \mathrm{Cu}$, and $\mathrm{Mg}$ ) and several essential amino acids. These metabolites are under strong environmental influence, while genotypic differences account for large differences as demonstrated by several authors [32,36]. Values of chlorophylls highlighted in our results were comparable to those found by Turkyilmaz Unal et al. (2013) [37] in Origanum sipyleum with important variations depending on soil type and altitudes under which the plants are grown. Indeed, chlorophylls content shows a decreasing trend when altitude increases, slightly acidic soils with deficient in potassium are generally preferred by species belonging to Origanum genus as concluded by the same authors.

\subsection{Chemical composition of OCEOs.}

Combined analyses of variance for OCEOs yield and individual chemical compounds are presented in Table 3. From these outcomes, all dependent variables were mainly under the dependency of extraction technique (as the main variability source) it since explained over 57\% for both p-cymene and terpinolene and about $88 \%$ of the total variability in the remaining variables. Replicate was of lesser extent ( $4 \%$ of the total variance), while the extraction technique by replicate interaction was of important magnitude only in the case of p-cymene and terpinolene, with around $38 \%$ of the total variance.

Table 3. Mean squares from the combined analyses of variance for EO yield (\%), \% of total compounds, and individual chemical compounds of OCEO isolated using two extraction techniques microwave (MW) and Clevenger hydrodistillation (HD) from aerial parts of $O$. compactum collected from central-northern Morocco. $\mathrm{Df}=$ degree of freedom and $\mathrm{EO}=$ essential oil.

\begin{tabular}{|c|c|c|c|}
\hline & Source of variation & & \\
\hline & Extraction techique (ET) & Replicate (R) & $\mathbf{E T} \times \mathbf{R}$ \\
\hline Df & 1 & 2 & 2 \\
\hline p-cymene $\left(\times 10^{-2}\right)$ & 1.22 & 0.21 & 1.21 \\
\hline Thymol & 21.06 & 1.29 & 0.78 \\
\hline Carvacrol & 4.91 & 0.01 & 0.48 \\
\hline$\alpha$-thujene & 0.829 & 0.017 & 0.018 \\
\hline$\alpha$-pinene $\left(\times 10^{-4}\right)$ & 21 & 0.66 & 2.33 \\
\hline
\end{tabular}




\begin{tabular}{|c|c|c|c|}
\hline & Source of variation & & \\
\hline & Extraction techique (ET) & Replicate (R) & $\mathbf{E T} \times \mathbf{R}$ \\
\hline Caryophyllene oxide $\left(\times 10^{-4}\right)$ & 48.17 & 3 & 12.33 \\
\hline Methyl linolenate $\left(\times 10^{-4}\right)$ & 126.3 & 10.3 & 16.7 \\
\hline Ethyl linolenate $\left(\times 10^{-2}\right)$ & 27.7 & 0.7 & 2.4 \\
\hline Terpinolene $\left(\times 10^{-4}\right)$ & 16.3 & 0.7 & 7.0 \\
\hline$\beta$-linalool $\left(\times 10^{-4}\right)$ & 160.2 & 36.3 & 14.3 \\
\hline$\%$ of total compounds & 39.37 & 1.13 & 0.16 \\
\hline EO yield & 4.47 & 0.01 & 0.08 \\
\hline
\end{tabular}

Results regarding yields of EOs and chemical composition using both extraction techniques (microwave and Clevenger hydrodistillation) are illustrated in Table 4.

Table 4. Mean values of EO yield, \% of total compounds, and individual chemical compounds (determined using GC-MS) of OCEO isolated using two extraction techniques microwave (MW) and Clevenger hydrodistillation (HD) from aerial parts of $O$. compactum collected from central-northern Morocco. Values are given as mean \pm SD of triplicate determinations. Compounds are listed in the elution order. For each parameter, values followed by the same letter are not significantly different at $5 \%$ as a probability level. RT $=$ retention time and $\mathrm{EO}=$ essential oil.

\begin{tabular}{l|l|l|l|l|l} 
EO traits & $\mathbf{N}^{\circ}$ & & $\mathbf{R T}$ & $\mathbf{M W}$ & HD \\
\hline Chemical compounds & & & & & \\
\hline $\mathrm{p}$-cymene & 1 & & 5.157 & $0.50 \pm 0.03 \mathrm{a}$ & $0.59 \pm 0.08 \mathrm{a}$ \\
\hline Thymol & 2 & & 5.438 & $\mathbf{7 8 . 8 1} \pm 0.22 \mathrm{a}$ & $\mathbf{7 5 . 0 7 \pm 0 . 9 9 \mathrm { b }}$ \\
\hline Carvacrol & 3 & & 6.471 & $\mathbf{1 4 . 8 4} \pm 0.39 \mathrm{a}$ & $\mathbf{1 3 . 0 3} \pm 0.30 \mathrm{~b}$ \\
\hline$\alpha$-thujene & 4 & & 6.762 & $0.00 \pm 0.00 \mathrm{~b}$ & $0.74 \pm 0.13 \mathrm{a}$ \\
\hline$\alpha$-pinene & 5 & & 7.093 & $0.06 \pm 0.02 \mathrm{a}$ & $0.06 \pm 0.03 \mathrm{a}$ \\
\hline Caryophyllene oxide & 6 & & 7.224 & $0.08 \pm 0.03 \mathrm{a}$ & $0.03 \pm 0.01 \mathrm{~b}$ \\
\hline Methyl linolenate & 7 & & 7.845 & $0.38 \pm 0.04 \mathrm{a}$ & $0.35 \pm 0.07 \mathrm{a}$ \\
\hline Ethyl linolenate & 8 & & 10.243 & $0.83 \pm 0.09 \mathrm{a}$ & $0.40 \pm 0.09 \mathrm{~b}$ \\
\hline Terpinolene & 9 & & 12.249 & $0.04 \pm 0.03 \mathrm{a}$ & $0.04 \pm 0.02 \mathrm{a}$ \\
\hline$\beta$-linalool & 10 & & 12.299 & $0.03 \pm 0.02 \mathrm{~b}$ & $0.13 \pm 0.05 \mathrm{a}$ \\
\hline Total & & & - & $95.57 \pm 0.33 \mathrm{a}$ & $90.45 \pm 0.73 \mathrm{~b}$
\end{tabular}

According to these results, significant variations were highlighted between the two techniques used for EO isolation in terms of yield, $\%$ of total compounds, and individual chemical compounds. Moreover, microwave extraction showed its superiority for almost chemical compounds, $\%$ total compounds, and EO yield. In contrast, Clevenger hydrodistillation (HD) had the best scores of p-cymene, $\beta$-linalool, and $\alpha$-thujene, which was absent in the case of microwave extraction.

Following Lucchesi et al. (2004) [20] and Bousbia et al. (2009) [38], MW method has several advantages over traditional alternatives such as shorter isolation time (15 min against $3 \mathrm{~h}$ required for hydrodistillation), environmental impact (lower energy cost), a cleaner method (since no residue generation and no solvents used), enhances antimicrobial and antioxidant activity, and provides more valuable EOs (higher amount of oxygenated phytocompounds).

MW extraction as a green analytical technique is widely used to isolate EO from aromatic and medicinal plants, but also to extract neutraceuticals from some foods [21-24]. In the literature, EOs yields and chemical composition were compared between MW and HD. In this context, EOs isolated using HD were found to have higher yields, $\%$ of total compounds, and oxygenated monoterpenes (like thymol and carvacrol) but lower values of monoterpene hydrocarbons (such as $\alpha$-pinene, $\alpha$-thujene, and terpinolene) as compared to the conventional HD technique [21,39]. As explained in Filly et al. (2014) [21], the higher percentage of oxygenated monoterpenes obtained MW is likely due to the fact that technique causes less hydrolytic and intense thermal effects than HD, which uses a large amount of water. Moreover, oxygenated compounds possess a high dipolar moment and interact more vigorously with 
microwaves and can, therefore, be extracted more easily than monoterpene hydrocarbons, which are known to have low dipolar moments.

OCEO yields, obtained by both techniques, were expressed as percentages of plant dry weight. As shown in Table 4, EO yield obtained by microwave $(7.41 \pm 0.11 \%)$ was higher than that achieved using hydrodistillation $(5.68 \pm 0.18 \%)$. The $\%$ of total compounds was significantly higher in the case of microwave isolation $(95.57 \pm 0.33 \%)$ than in Clevenger hydrodistillation $(90.45 \pm 0.73 \%)$. For the microwave method, the obtained chromatogram (Fig. 2) for OCEO chemical composition was characterized by 9 chemical compounds (Table 4) against 10 compounds for Clevenger hydrodistillation, as revealed by the chromatogram in Fig. 3 accounting for $96.9 \%$ of the total chemical composition. In both techniques, thymol and carvacrol were the major constituents (their concentrations exceeded $1 \%$ ), while the remaining compounds were in concentrations lower than $1 \%$. Thymol and carvacrol were found to be $78.81 \pm 0.22$ and $14.84 \pm 0.39 \%$, respectively, in the case of microwave (MW) against 75.07 \pm 0.99 and $13.03 \pm 0.30 \%$ for Clevenger hydrodistillation (HD). From these outcomes, it seems that OCEO was a thymol chemotype. Owing to its numerous health-healing properties and biotechnological applications such as the food industry, $O$. compactum phytochemistry has received much attention.

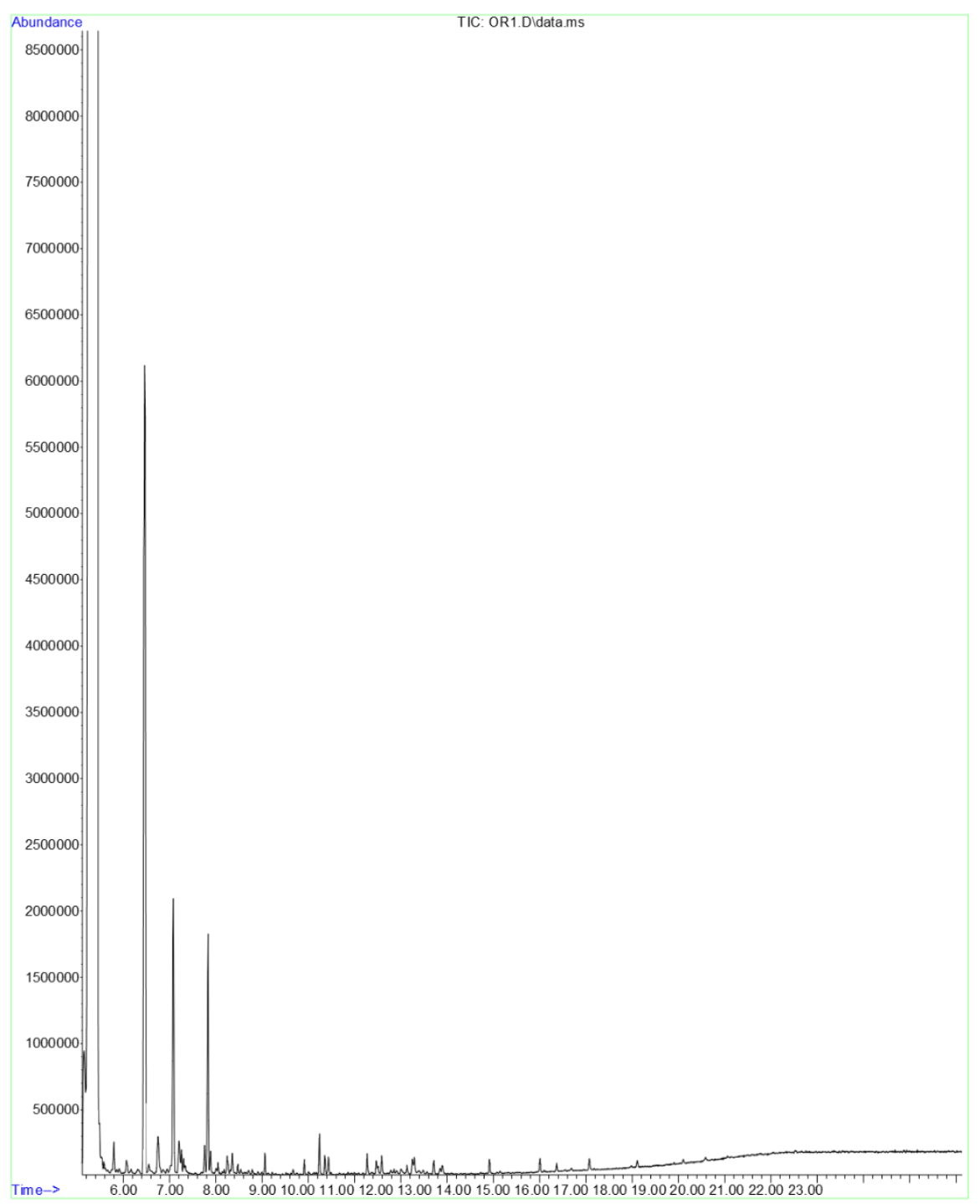

Figure 2. A representative typical GC-MS total ion current (TIC) chromatogram of essential oil isolated using microwave-assisted extraction from aerial parts (dried flowers) of $O$. compactum harvested from central-northern Morocco. 
A literature review shows that OCEO yield and chemical composition vary widely depending on several factors such as plant parts used for EO isolation, phenological stage, the geographical area under which plants are grown, harvest season, isolation techniques, and conditions, which include temperature, duration, among others [13,15-18,40-43]. The EOs yield values reported in our results were consistent with Bouyahya et al. (2017) [17]. These authors investigated OCEO yields and chemical composition according to various phenological stages; they found that the best record of yield is $5.7 \%$ (at the vegetative stage), which decreased to reach its minimum $(2.9 \%)$ at the post-flowering stage. While studying 36 samples from various sites in northern Morocco, Bakhy et al. (2014) [15] found slightly lower values of OCEO yields $(0.31-2.44 \%)$. Likewise, similar trends (1.22-4.24\%) were observed by Laghmouchi et al. (2018) [18].

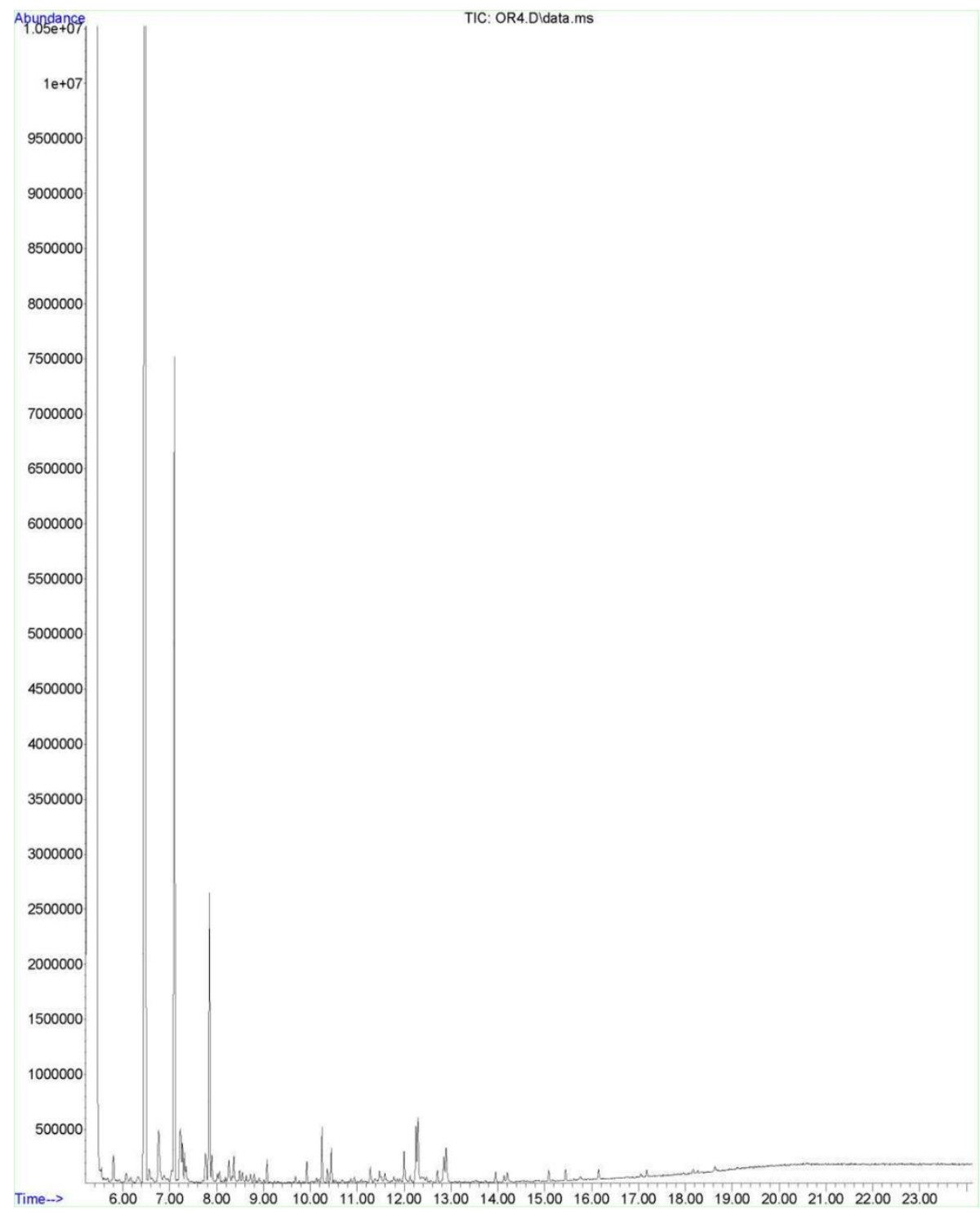

Figure 3. A representative typical GC-MS total ion current (TIC) chromatogram of essential oil isolated using Clevenger hydrodistillation from aerial parts (dried flowers) of $O$. compactum harvested from central-northern Morocco.

With respect to chemical composition, a wide range of constituents of various chemical groups (mainly oxygenated monoterpenes and monoterpenes hydrocarbons) were reported in OCEOs from different areas as reviewed recently in Bouyahya et al. (2020) [13]. Aboukhalid et al. (2016) [16] studied the chemical composition of 88 O. compactum populations from 
several bioclimatic regions across Morocco; they found an important chemotypic diversity with the dominance of six compounds: carvacrol (0-96.3\%), thymol (0-80.7\%), p-cymene $(0.2-$ $58.6 \%), \gamma$-terpinene $(0-35.2 \%)$, carvacryl methyl oxide ( $0-36.2 \%)$, and $\alpha$-terpineol $(0-25.8 \%)$. In spite of this chemical diversity, an overview of the published literature let conclude that the major compounds found in OCEO are the following: Carvacrol, thymol, p-cymene, and $\gamma$ terpinene $[13,17]$. This chemical diversity is responsible for numerous biological activities of OCEO, including antioxidant, antimicrobial, anticancer, and antiparasitic activities [13].

As synthesized in the review compiled by Costa et al. (2019) [44], both thymol and carvacrol endowed with an important antioxidant power together with wound healing and antiinflammatory properties, which justify their wide uses in the pharmaceutical industry. Following the same authors, these two monoterpenes are able to modulate the release of reactive species such as nitric oxide, pro-inflammatory cytokines, and growth factors associated with the initial stages of the healing process. Likewise, EO rich in thymol and carvacrol were demonstrated to have antimicrobial activities against several pathogens $[5,13]$. Mechanisms of action of thymol and carvacrol, as antimicrobial agents, are not yet fully elucidated; however, the main cascade of events underlying such mechanism are the following: (1) structural and functional alterations affect cellular membranes; (2) the interference of nucleic acids in both functionality and synthesis; (3) the coagulation of cytoplasm and leakage of some vital cytoplasmic constituents; (4) the imbalance of metabolism; (5) the interruption of the cellular communication via the inhibition of quorum sensing $[13,45]$.

\subsection{Principal component analysis (PCA).}

PCA was used as a multivariate statistical approach to discriminate between techniques used for OCEO isolation based on several dependant variables (OCEO yield, \% of total compounds, and individual compounds). The first two principal components (PCs) were retained since they explained over $84 \%$ of the total data variability.

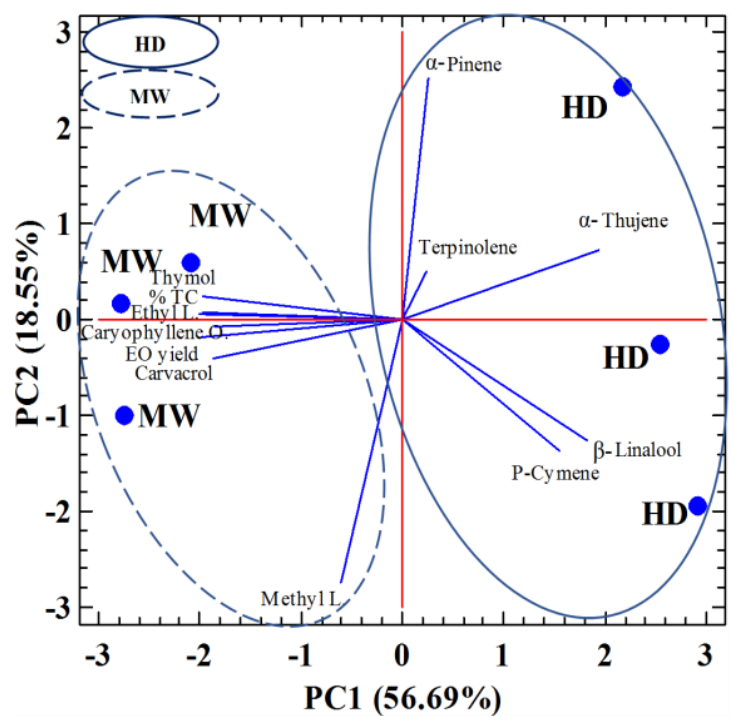

Figure. 4. Principal component analysis (PCA) projections on PC1 and PC2. Eigenvalues are symbolized as blue segments representing parameters that most affect each principal component. The 6 plotted points are linked to both techniques: Hydrodistillation (HD) and microwave (MW) used for the isolation of essential oil obtained from dried flowers of $O$. compactum. $\mathrm{EO}=$ essential oil, $\% \mathrm{TC}=$ percentage of total compounds, Methyl L. = Methyl linolenate, and Ethyl L. = Ethyl linolenate. 
Points plotted on the surface delimited by axis 1, and 2 (Fig. 4) are related to OCEO isolation techniques, which seem to be distributed along with the first component (PC1), which accounted for about $65.69 \%$ of the total data variability. Furthermore, toward the positive side of PC1, HD (Clevenger hydrodistillation) interacted with higher records of $\alpha$-pinene, $\alpha$-thujene, $\beta$-linalool, and p-cymene. In contrast, great records of EO yields, $\%$ of total compounds, thymol, carvacrol, caryophyllene oxide, methyl linoleate, and ethyl linolenate were associated with MW (microwave extraction) on the negative side of PC1. In addition, terpinolene was close to zero, with lower values in both techniques. PCA outcomes confirmed mean values comparison pooled in Table 4. PCA was successfully used to clearly discriminate among genotypes and environments based on phytochemicals [16,46], allowing an orthogonal reduction of investigated variables.

\section{Conclusions}

Based on the results highlighted above, a set of conclusions could be drawn. OCEO isolated via microwave-assisted method showed its superiority over the conventional Clevenger hydrodistillation in terms of yield, $\%$ of total compounds, and almost individual compounds. These results were confirmed by principal component analysis mostly through the first component, which accounted for over $65 \%$ of the data variability. As demonstrated by chemical screening, $O$. compactum was found to be a rich source of proteins, minerals, and pigments (chlorophylls a and b). Likewise, eight amino acids were also revealed. Among them, Leu and Ile were essential. Important amounts of mineral elements were found in $O$. compactum, mainly $\mathrm{K}, \mathrm{Ca}, \mathrm{Mg}$ as macronutrients, while $\mathrm{Fe}$, along with $\mathrm{Mn}$, were the main micronutrients. In both cases (microwave and Clevenger hydrodistillation methods), OCEOs chemical composition were dominated by thymol (over 75\%) and carvacrol (more than 13\%). The microwave might be suggested for EO isolation as a green, more efficient, and fast method. Supplementary investigations are needed for the optimization of parameters involved in microwave-assisted extraction, such as time and the apparatus power to achieve the best yield and chemical composition records.

\section{Funding}

This research received no external funding.

\section{Acknowledgments}

The authors are grateful to Dr. Taha El Kamli (Laboratory of Biological Tests, Food and Nutritional Transition Team (ETAN), Ibn Tofail University, Morocco) for his kind technical assistance.

\section{Conflicts of Interest}

The authors declare no conflict of interest.

\section{References}

1. Rankou, H.; Culham, A.; Jury, S.L; Christenhusz, M. The endemic flora of Morocco. Phytotaxa 2013, 78, 1-69, https://doi.org/10.11646/phytotaxa.78.1.1. 
2. Bakha, M.; Al Faiz, C.; Daoud, M.; El Mtili, N.; Aboukhalid, K.; Khiraoui, A.; Machon, N.; Silijak Yakovlev, S. Genome size and chromosome number for six taxa of Origanum genus from Morocco. Bot Lett 2017, 164, 361-370, https://doi.org/10.1080/23818107.2017.1395766.

3. Reardon, S. Antibiotic resistance sweeping developing world: bacteria are increasingly dodging extermination as drug availability outpaces regulation. Nature 2014, 509, 141-143, https://doi.org/10.1038/509141a.

4. Bouyahya, A.; Lagrouh, F.; El Omari, N.; Bourais, I.; El Jemli, M.; Marmouzi, I.; Salhi, N.; Faouzi, M.E.A.; Belmehdi, O.; Dakka, N.; Bakri, Y. Essential oils of Mentha viridis rich phenolic compounds show important antioxidant, antidiabetic, dermatoprotective, antidermatophyte and antibacterial properties. Biocat Agric Biotechnol 2020, 23, https://doi.org/10.1016/j.bcab.2019.101471.

5. Jugreet, B.S.; Mahomoodally, M.F. Essential oils from 9 exotic and endemic medicinal plants from Mauritius shows in vitro antibacterial and antibiotic potentiating activities. S Afr J Bot 2020, 132, 355-362, https://doi.org/10.1016/j.sajb.2020.05.001.

6. Lekmine, S.; Boussekine, S.; Kadi, K.; Martín-García, A.I.; Kheddouma, A.; Nagaz, K.; Bensouici, C. A comparative study on chemical profile and biological activities of aerial parts (stems, flowers, leaves, pods and seeds) of Astragalus gombiformis. Biocat Agric Biotechnol 2020, 27, https://doi.org/10.1016/j.bcab.2020.101668.

7. Saleem, H.; Htar, T.T.; Naidu, R.; Ahmad, I.; Zengin, G.; Ahmad, M.; Ahemad, N. Investigations into the therapeutic effects of aerial and stem parts of Buxus papillosa CK Schneid.: In vitro chemical, biological and toxicological perspectives. J Pharmaceut Biomed 2019, 166, 128-138, https://doi.org/10.1016/j.jpba.2019.01.007.

8. Llorent-Martinez, E.J.; Ruiz-Riaguas, A.; Sinan, K.I.; Bene, K.; Fernandez-de Cordova, M.L.; Picot-Allain, C.; Mahomoodally, F.; Saleem, H.; Zengin, G. Exploring chemical profiles and bioactivities of Harungana madagascariensis Lam. ex Poir. Leaves and stem bark extracts: a new source of procyanidins. Anal Lett 2020, 53, 399-412, https://doi.org/10.1080/00032719.2019.1653903.

9. Nisar, B.; Sultan, A.; Rubab, S.L. Comparison of medicinally important natural products versus synthetic drugs-a short commentary. Nat Prod Chem Res 2017, 6, https://doi.org/10.4172/2329-6836.1000308.

10. Zeroual, A.; Eloutassi, N.; Sakar, E.H.; Nechad, I.; Louaste, B.; Lahkimi, A.; Chaouch, M.; Chaqroune, A. Antimicrobial and antioxidant activities of crude extracts and essential oils from two thyme species: Thymus vulgaris and Thymus hyemalis from northern Morocco. Int J Biosci 2018, 12, 391-399.

11. Al-Dhafri, K.; Ching, C.L.; Karsani, S.A. Purification and characterization of antimicrobial peptide fractions of Junipers seravschanica. Biocat Agric Biotechnol 2020, https://doi.org/10.1016/j.bcab.2020.101554.

12. Hamilton, A. Medicinal plants and conservation: Issues and approaches. International Plants Conservation Unit, WWF-UK: Surrey, UK, 2003; pp. 1-51.

13. Bouyahya, A.; Zengin, G.; Belmehdi, O.; Bourais, I.; Chamkhi, I.; Taha, D.; Benali T.; Dakka, N.; Bakri, Y. Origanum compactum Benth., from traditional use to biotechnological applications. J Food Biochem 2020, https://doi.org/10.1111/jfbc.13251.

14. Ait-Sidi-Brahim, M.; Markouk, M.; Larhsini, M. Moroccan Medicinal Plants as Antiinfective and Antioxidant Agents. In New Look to Phytomedicine: Advancements. In: Herbal Products as Novel Drug. Khan, M.S.A.; Ahmad, I.; Chattopadhyay, D. Eds.; Academic Press: London, UK, 2019; pp. 91-142, https://doi.org/10.1016/B978-0-12-814619-4.00005-7.

15. Bakhy, K.; Benlhabib, O.; Bighelli, A.; Casanova, J.; Tomi, F.; Al Faiz, C. Yield and chemical variability of the essential oil isolated from aerial parts of wild Origanum compactum Benth From Moroccan Western Rif. Am J Essent Oil Nat Prod 2014, 1, 9-17.

16. Aboukhalid, K.; Lamiri, A.; Agacka-Mołdoch, M.; Doroszewska, T.; Douaik, A.; Bakha, M.; Casanova, J.; Tomi, F.; Machon, N.; Al Faiz, C. Chemical polymorphism of Origanum compactum grown in all natural habitats in Morocco. Chem Biodiv 2016, 13, 1126-1139, https://doi.org/10.1002/cbdv.201500511.

17. Bouyahya, A.; Dakka, N.; Talbaoui, A.; Et-Touys, A.; El-Boury, H.; Abrini, J.; Bakri, Y. Correlation between phenological changes, chemical composition and biological activities of the essential oil from Moroccan endemic Oregano (Origanum compactum Benth). Ind Crop Prod 2017, 108, 729-737, http://dx.doi.org/10.1016/j.indcrop.2017.07.033.

18. Laghmouchi, Y.; Belmehdi, O.; Senhaji, N.S.; Abrini, J. Chemical composition and antibacterial activity of Origanum compactum Benth. essential oils from different areas at northern Morocco. S Afr J Bot 2018, 115, 120-125, https://doi.org/10.1016/j.sajb.2018.02.002.

19. Chahbi, A.; Nassik, S.; El Amri, H.; Douaik, A.; El Maadoudi, E.H.; Boukharta, M.; El Hadrami, E.M. Chemical Composition and Antimicrobial Activity of the Essential Oils of Two Aromatic Plants Cultivated in Morocco (Cinnamomum cassia and Origanum compactum). $J$ Chem 2020, 2020, https://doi.org/10.1155/2020/1628710.

20. Lucchesi, M.E.; Chemat, F.; Smadja, J. Solvent-free microwave extraction of essential oil from aromatic herbs: comparison with conventional hydrodistillation. J Chromatogr A 2004, 1043, 323-327, https://doi.org/10.1016/j.chroma.2004.05.083. 
21. Filly, A.; Fernandez, X.; Minuti, M.; Visinoni, F.; Cravotto, G.; Chemat, F. Solvent-free microwave extraction of essential oilfrom aromatic herbs: from laboratory to pilot and industrial scale. Food Chem 2014, 150, 193-198, http://dx.doi.org/10.1016/j.foodchem.2013.10.139.

22. Fathi-Achachlouei, B.; Azadmard-Damirchi, S.; Zahedi, Y.; Shaddel, R. Microwave pretreatment as a promising strategy for increment of nutraceutical content and extraction yield of oil from milk thistle seed. Ind Crops Prod 2019, 128, 527-533, https://doi.org/10.1016/j.indcrop.2018.11.034.

23. Hayat, K.; Zhang, X.; Qamar, S.; Hussain, A.; Tahir, M.U.; Hussain, S. Microwave heating as a tool to enhance antioxidant activity and release soluble conjugates from Feutrell's Early (citrus mandarin cultivar) peels. J Food Process Pres 2020, https://doi.org/10.1111/jfpp.14574.

24. Karrar, E.; Sheth, S.; Wei, W.; Wang, X. Effect of microwave heating on lipid composition, oxidative stability, color value, chemical properties, and antioxidant activity of gurum (Citrulluslanatus var. Colocynthoide) seed oil. Biocatal Agric Biotechnol 2020, 23, https://doi.org/10.1016/j.bcab.2020.101504.

25. Pizzale, L.; Bortolomeazzi, R.; Vichi, S.; Überegger, E.; Conte, L.S. Antioxidant activity of sage (Salvia officinalis and S. Fructicosa) and oregano (Origanum onites and O. inderscedens) extracts related to their phenolic compound content. J Sci Food Agric 2002, 82, 1645-1651, https://doi.org/10.1002/jsfa.1240.

26. Lichtenthaler, H.K. Chlorophylls and carotenoids: pigments of photosynthetic biomembranes. Method Enzymol 1987, 148, 350-382, https://doi.org/10.1016/00766879(87)48036-1.

27. Horwitz, G.L.W. Official methods of analysis. Association of Official Analytical Chemists (AOAC) International, 18th ed. AOAC International: Gaithersburg, USA, 2005.

28. Agusa, T.; Kunito, T.; Yasunaga, G.; Iwata, H.; Subramanian, A.; Ismail, A.; Tanabe, S. Concentrations of trace elements in marine fish and its risk assessment in Malaysia. Mar Pollut Bull 2005, 51, 896-911, https://doi.org/10.1016/j.marpolbul.2005.06.007.

29. Harborne, J.B. Phytochemical Methods: A guide to modern techniques of plant analysis. Chapman and Hall: New York, USA, 1973.

30. Jennan, S.; Fouad, R.; Nordine, A.; Farah, A.; Bennani, B.; Moja, S.; Greche, H.; Mahjoubi, F. Chemical Composition and Antibacterial Screening of Aerial Parts of Essential Oils of Three Satureja species (Satureja briquetti, Satureja atlantica and Satureja alpina) Growing Wild in the Middle Atlas Mountains of Morocco. J Essent Oil Bear Pl 2018, 21, 741-748, https://doi.org/10.1080/0972060X.2018.1486230.

31. Talbaoui, A.; El amdaoui, H.; El Moussaouiti, M.; Aneb, M.; Amzazi, S.; Bakri, Y. GC-MS analysis and antibacterial activity of hydro-distitllation oil from Tetraclinis articulata wood grown in Khemisset (Morocco). J Indian Acad Wood Sci 2016, 13, 114-117, https://doi.org/10.1007/s13196-016-0173-7.

32. Pereira, C.; Barros, L.; Ferreira, I.C.F.R. A comparison of the nutritional contribution of thirty-nine aromatic plants used as condiments and/or herbal infusions. Plant Foods Hum Nutr 2015, 70, 176-183, https://doi.org/10.1007/s11130-015-0476-7.

33. Jabeur, I.; Pereira, E.; Barros, L.; Calhelha, R.C.; Soković, M.; Oliveira, M.B.P.P.; Ferreira, I.C.F.R. Hibiscus sabdariffa L. as a source of nutrients, bioactive compounds and colouring agents. Food Res Int 2017, 100, 717-723, https://doi.org/10.1016/j.foodres.2017.07.073.

34. Pires, T.C.; Dias, M.I.; Barros, L.; Ferreira, I.C. Nutritional and chemical characterization of edible petals and corresponding infusions: Valorization as new food ingredients. Food Chem 2017, 220, 337-343, https://doi.org/10.1016/j.foodchem.2016.10.026.

35. Fernandes, F.; Pereira, E.; Círić, A.; Soković, M.; Calhelha, R.C.; Barros, L.; Ferreira, I.C.F.R. Ocimum basilicum var. purpurascens leaves (red rubin basil): A source of bioactive compounds and natural pigments for the food industry. Food Func 2019, 10, 3161-3171, https://doi.org/10.1039/c9fo00578a.

36. Saleh, A.M.; Abdel-Mawgoud, M.; Hassan, A.R.; Habeeb, T.H.; Yehia, R.S.; Abd Elgawad, H. Global metabolic changes induced by arbuscular mycorrhizal fungi in oregano plants grown under ambient and elevated levels of atmospheric $\mathrm{CO}_{2}$. Plant Physiol Bioch 2020, 151, 255-263, https://doi.org/10.1016/j.plaphy.2020.03.026.

37. Turkyilmaz Unal, B.; Guvensen, A.; Dereboylu, E.A.; Ozturk, M. Variations in the proline and total protein contents in Origanum sipyleum L. from different altitudes of spil mountain, Turkey. Pak J Bot 2013, 45, 571-576.

38. Bousbia, N.; Vian, M.A.; Ferhat, M.A.; Petitcolas, E.; Meklati, B.Y.; Chemat, F. Comparison of two isolation methods for essential oil from rosemary leaves: Hydrodistillation and microwave hydrodiffusion and gravity. Food Chem 2009, 114, 355-362, https://doi.org/10.1016/j.foodchem.2008.09.106.

39. Khazayi, M.; Afshari, H., Hashemi-Moghaddam, H. Evaluation of Extraction Method and Chemical Modifier on Chemical Composition of the Essential Oils from the Roots of Rosa canina L. J Essent OilBear Plants 2019, 22, 131-140, https://doi.org/10.1080/0972060X.2019.1604167.

40. Belkamel, A.; Bammi, J.; Belkamel, A.; Douira, A. Etude de la composition chimique de l'huile essentielle d'une endémique Ibéro-marocaine: Origanum compactum (Benth.). J Anim Plant Sci 2013, 19, 2880-2887.

41. Bouyahya, A.; Guaouguaou, F.E.; Dakka, N.; Bakri, Y. Pharmacological activities andmedicinal properties of endemic Moroccan medicinal plant Origanum compactum (Benth) and their main compounds. Asian Pac J Trop Dis 2017, 7, 628-640, https://doi.org/10.12980/apjtd.7.2017D7-31.

42. Stankov, S.; Fidan, H.; Stefanova, G.; Kostova, I.; Damyanova, S.; Dimitrova-Dyulgerova, I.; Ercisli, S.; Stoyanova, A. Chemical Composition and Antimicrobial Activity of Essential Oil from Aerial Part (Leaves 
and Fruit) of Eucalyptus gomphocephala DC. J Essent Oil Bear Pl 2020, 23, 204-212, https://doi.org/10.1080/0972060X.2020.1727365.

43. Zeroual, A.; Eloutassi, N.; Chaouch, M.; Chaqroune, A. Antimicrobial, antioxidant activity, and chemical composition of Origanum compactum benth from taounate province, north Morocco. Asian J Pharm Clin Res 2020, 13, 126-131, http://dx.doi.org/10.22159/ajpcr.2020.v13i3.36319.

44. Costa, M.F.; Durço, A.O.; Rabelo, T.K.; Barreto, R.; de, S.S.; Guimarães, A.G. Effects of carvacrol, thymol and essential oils containing such monoterpenes on wound healing: A systematic review. J Pharm Pharmacol 2019, 71, 141-155, https://doi.org/10.1111/jphp.13054.

45. Marinelli, L.; Di Stefano, A.; Cacciatore, I. Carvacrol and its derivatives as antibacterial agents. Phytochemistry Rev 2018, 17, 903-921, https://doi.org/10.1007/s11101-018-9569-x.

46. Sakar, E.H.; El Yamani, M.; Rharrabti, Y. Variability of oil content and its physico-chemical traits from five almond (Prunis dulcis) cultivars grown in northern Morocco. J Mater Environ Sci 2017, 8, 2679-2686. 